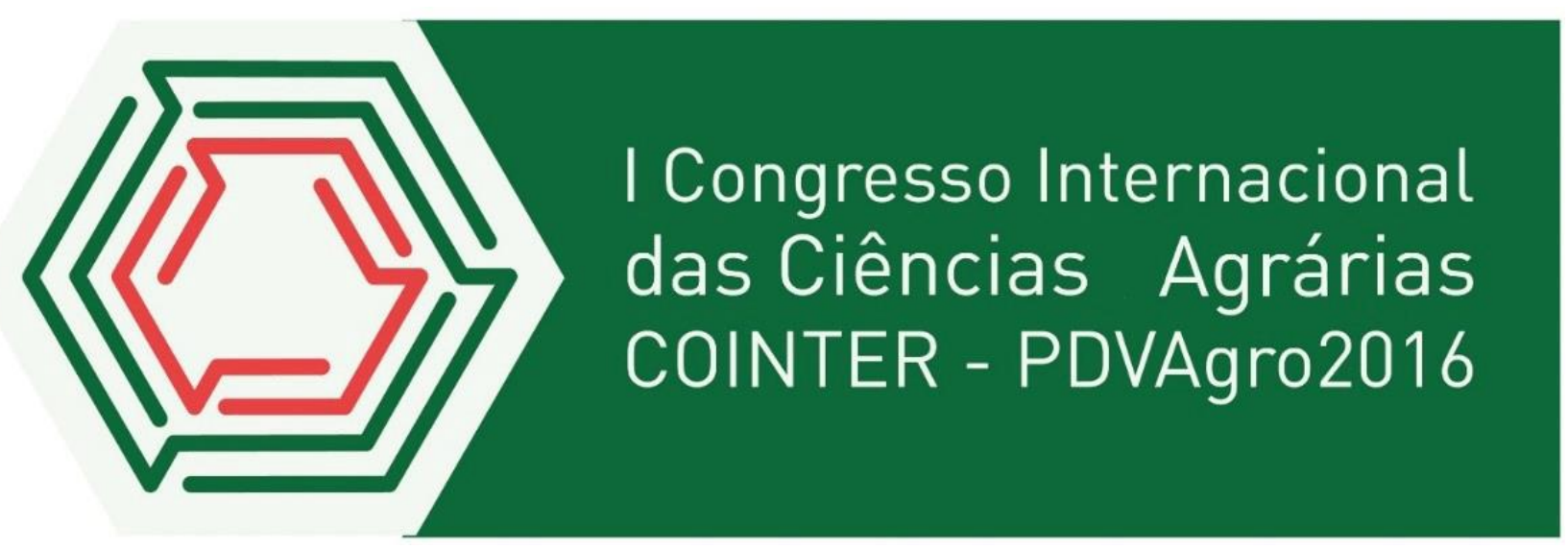

\title{
AMOSTRAGEM PARA DETERMINAÇÃO DA ATIVIDADE DA REDUTASE DO NITRATO EM FOLHAS DE CANA-DE-AÇÚCAR \\ Apresentação: Comunicação Oral
}

\begin{abstract}
José de Arruda Barbosa ${ }^{1}$; Victor Hugo de Farias Guedes ${ }^{2}$; Maria José Alves de Moura ${ }^{3}$; Larissa Grasiela de Arruda Ferreira Costa; Renato Lemos dos Santos ${ }^{4}$.
\end{abstract}

\begin{abstract}
Resumo
A assimilação de $\mathrm{N}$ depende da atividade da redutase do nitrato. A enzima se encontra presente em folhas e em raízes, mas devido a facilidade de amostragem, as folhas são mais utilizadas. Métodos amostrais de folhas em experimentação de campo com cana-de-açúcar são fundamentais para determinação da atividade máxima da enzima, para que haja representatividade da população e conclusões verdadeiras a cerca da resposta da enzima. O objetivo deste trabalho foi sugerir um método de amostragem de coleta de folhas de cana-de-açúcar para determinar a atividade da redutase do nitrato (ARN), que aborde quando, durante o ciclo da cultura, se deve amostrar, onde coletar as amostras nas plantas, quantas amostras se deve coletar e em que período do dia a coleta é mais adequada. Em quatro ensaios foi possível determinar qual o período do ciclo da cultura deve ser utilizado para a coleta de folhas; qual a folha mais adequada para coleta; qual o número ideal de folhas para coletar; qual o período do dia em que a enzima tem atividade máxima. A avaliação da ARN em cana-de-açúcar deve ocorrer entre 95 e 100 dias após o plantio e pode ser realizada em qualquer folha verde. Em experimentos de campo recomenda-se a coleta de 15 folhas, que deve ocorrer entre 12:00 e 12:30 h.
\end{abstract}

\footnotetext{
${ }^{1}$ Bacharelado em agronomia , Instituto Federal de Educação, Ciência e tecnologia de Pernambuco Campus Vitoria de Santo Antão, josearruda777@gmail.com

${ }^{2}$ Bacharelado em agronomia , Instituto Federal de Educação, Ciência e tecnologia de Pernambuco Campus Vitoria de Santo Antão, victorhguedes1@gmail.com

${ }^{3}$ Bacharelado em agronomia , Instituto Federal de Educação, Ciência e tecnologia de Pernambuco Campus Vitoria de Santo Antão, mariamouraalves@gmail.com

${ }^{4}$ Bacharelado em agronomia , Instituto Federal de Educação, Ciência e tecnologia de Pernambuco Campus Vitoria de Santo Antão,grasielalala@gmail.com

${ }^{5}$ Doutor em Ciências do Solo/Docente/Coordenado do Departamento de Pesquisa e Extensão IFPE Campus Vitoria de Santo Antão, renato.santos@vitoria.ifpe.edu.br
} 
Palavras-Chave: folhas diagnósticas, atividade enzimática, assimilação de nitrogênio.

\section{Introdução}

$\mathrm{Na}$ literatura é possível encontrar trabalhos que discutem o tamanho da amostra foliar para avaliação nutricional das culturas (Holland et al., 1967; Orlando Filho e Campos, 1975a,b; Rosseti et al., 1991; Rozane et al., 2009; Hernandes et al., 2011). Entretanto, pouco se conhece sobre o processo de amostragem para determinação da ARN, como: definição do número de folhas da amostra; definição da folha mais adequada; horário mais propício do dia para coleta da folha; e período ideal do ciclo da cultura. O conhecimento destes questionamentos pode possibilitar a obtenção da expressão mais adequada do comportamento da ARN em cana-de-açúcar.

Metodologias para determinação da ARN foram desenvolvidas e aprimoradas em diferentes plantas e regiões com condições climáticas diferentes. Assim, é necessário um estudo mais específico para cana-de-açúcar desenvolvida geneticamente sob condições tropicais no Brasil. No Brasil, apenas o trabalho realizado por Santos et al. (2014) pesquisou a necessidade da utilização do vácuo e do tempo de incubação do tecido foliar em cana-de-açúcar. A necessidade de estabelecer uma metodologia específica para cana-de-açúcar motivaram a realização deste trabalho

\section{Fundamentação Teórica}

A cana-de-açúcar (Saccharum spp.) é uma importante cultura no cenário agrícola mundial por ser matéria prima para diversos usos, desde gêneros alimentícios a biocombustíveis, como açúcar e etanol, respectivamente. O Brasil é o maior produtor e exportador de açúcar e etanol do mundo, tendo sido prevista uma produção de 34,6 milhões de toneladas de açúcar e 29,2 bilhões de litros de etanol para a safra 2015/16 (CONAB, 2015).

Elevadas produções de açúcar e etanol só são possíveis com aumento da produção de matéria prima. Assim, aumentar a produção agrícola de cana-de-açúcar significa aumento da demanda por nutrientes, principalmente N, P e K (Freire et al., 2015).

O N é um dos mais absorvidos pela cultura (Trivelin et al., 2013; Oliveira, et al., 2016). As plantas absorvem o $\mathrm{N}$, preferencialmente na forma amoniacal e nítrica. Para a assimilação do $\mathrm{N}$ nítrico, as plantas precisam reduzi-lo à forma amoniacal nos plastídios radiculares ou nos cloroplastos. Na fase inicial desse processo, a enzima redutase do nitrato é responsável pela redução de nitrato a nitrito (Hirel et al., 2011). Assim, estudos que avaliam a absorção e assimilação de N na forma nítrica, necessariamente avaliam a atividade da redutase do nitrato (ARN). 
A redutase do nitrato é uma flavoproteína formada por duas subunidades idênticas, compostas por flavina adenina dinucleotídeo, Fe-heme e molibdopterina. A enzima é encontrada no citossol das células corticais e nas células do mesófilo da parte aérea das plantas (Vaughn e Campbell, 1988; Campbell, 1999).

A técnica da amostragem é aplicada pela dificuldade de analisar e caracterizar todos os indivíduos de uma população. Para aplicação correta dessa técnica é necessária uma amostragem de caráter exploratória, com a coleta prévia de um número de indivíduos para se estabelecer a variabilidade de cada variável da população. Conhecendo a variabilidade dos atributos, considerando um limite de variação à média aceitável e um nível de probabilidade previamente estabelecido, pode-se estimar o número ideal de indivíduos para compor uma amostra, que seja representativa para a unidade amostral previamente definida (Rozane et al., 2009; Hernandes et al., 2011; Azevedo et al., 2013).

Alguns trabalhos arbitraram também que as análises para determinação da ARN devem ser realizadas após as plantas receberem de três a quatro horas de luz, justificando que esse tempo é suficiente para expressão máxima da enzima (Hagemam e Reed, 1980; Bezerra Neto e Barreto, 2011).

A atividade da enzima é determinada in vitro ou in vivo. O método in vitro é mais laborioso, porque necessita da extração da enzima, enquanto que no método in vivo é necessária apenas a incubação do tecido amostrado em meio nutritivo.

Os questionamentos nos métodos amostrais para determinação da ARN em diferentes plantas e regiões climáticas e a necessidade de estabelecer uma metodologia específica para canade-açúcar motivaram a realização deste trabalho com objetivo: sugerir um método de amostragem de coleta de folhas de cana-de-açúcar, que aborde quando durante o ciclo da cultura se deve amostrar, onde coletar as amostras nas plantas, quantas amostras se deve coletar e em que período do dia a coleta é mais adequada.

\section{Metodologia}

O trabalho foi dividido em quatro ensaios: a) Avaliação do período do ciclo da cana-deaçúcar ideal para realização da coleta de folhas para avaliar a ARN em experimentos de campo; b) Avaliação da posição ideal da folha de cana-de-açúcar para avaliar a ARN; c) Avaliação da coleta do número de folhas ideal para representar uma parcela e avaliar a ARN; d) Avaliação do período do dia ideal para realização da coleta de folhas para avaliar a ARN. 


\section{Métodos comuns de determinação da ARN utilizados em todos os ensaios}

Nos ensaios foi empregado o método in vivo proposto por Hagemam e Reed (1980), adaptado por Bezerra Neto e Barreto (2011) para determinação da ARN em folhas. Os tecidos vegetais coletados foram protegidos com papel alumínio e acondicionados em caixas térmicas contendo gelo até serem enviados ao laboratório para determinação da ARN. Segundo os autores, a coleta do tecido foliar deve ser realizada da seguinte forma: a) Quando a folha tiver sido exposta entre três e quatro horas de radiação solar; b) A folha para coleta deve ser a folha +1 ; e c) Recomenda a coleta de pelo menos três folhas por parcela útil em experimentos de campo.

Assim, discos de tecido foliar foram retirados do terço médio da folha recomendada, excluindo-se a nervura central, até atingirem 0,25 g de peso. Os discos foram incubados em $5 \mathrm{~mL}$ de uma solução nutritiva constituída de $\mathrm{K}_{2} \mathrm{HPO}_{4} 0,1 \mathrm{~mol} \mathrm{~L}{ }^{-1}, \mathrm{KNO}_{3} 0,1 \mathrm{~mol} \mathrm{~L}{ }^{-1}$, [n-propanol a $1 \%$ (v/v)] e [espalhante adesivo a $0,01 \%(\mathrm{v} / \mathrm{v})$ ], durante $1 \mathrm{~h}$ a $25{ }^{\circ} \mathrm{C}$, submetida uma vez ao vácuo de -80 kpa. A incubação foi realizada na ausência de luz.

Alíquota de $1 \mathrm{~mL}$ da solução foi coletada após a incubação e em um balão volumétrico de $10 \mathrm{~mL}$ foram adicionados mais $5 \mathrm{~mL}$ de uma solução de sulfanilamida $0,5 \%$, contendo $0,75 \mathrm{~mol} \mathrm{~L}^{-1}$ de $\mathrm{HCl}$ e $0,01 \%$ de $\mathrm{N}$-etilenodiaminadihidrocloreto (N-naftil), completando-se o volume com $4 \mathrm{~mL}$ de água deionizada. Após 15 minutos de reação, a leitura de absorbância dessa solução foi realizada em espectrofotômetro Biospectro ${ }^{\circledR}$, com sistema óptico mono feixe e sensibilidade de leituras nas faixas do ultravioletra e do visível, ajustado para comprimento de onda de $540 \mathrm{~nm}$.

Concomitantemente foi preparada uma curva padrão de absorbância em função das concentrações de $0,1,2,3,4$ e $5 \mu \mathrm{mol} \mathrm{L}^{-1}$ de nitrito na solução de leitura. Assim, a ARN foi estimada em $\mu \mathrm{mol} \mathrm{NO}{ }_{2}^{-} \mathrm{g}^{-1} \mathrm{~h}^{-1}$.

\section{Caracterização dos locais dos ensaios}

Todos os ensaios, com exceção do terceiro, foram realizados no campus Vitória de Santo Antão (CVSA), do Instituto Federal de Educação, Ciência e Tecnologia de Pernambuco (IFPE). O município de Vitória de Santo Antão - PE se localiza na mesorregião da mata pernambucana, com coordenadas geográficas de $08^{\circ} 07^{\prime}$ '05' ' de latitude sul e $35^{\circ} 17^{\prime} 29^{\prime \prime}$ ' de longitude oeste e 156 m de altitude. O município se encontra na zona de transição climática dos tipos: Aws e As, segundo classificação de Koeppen, com ligeira predominância do segundo, quente e úmido com chuvas máximas de abril a agosto e pluviosidade média anual de $1.309 \mathrm{~mm} \mathrm{ano}^{-1}$, com médias térmicas anuais de $27^{\circ} \mathrm{C}$. O solo no ambiente dos ensaios é o ARGISSOLO AMARELO (CPRM, 2005).

O terceiro ensaio foi realizado na Estação Experimental de Cana-de-açúcar de Carpina (EECAC), no município de Carpina - PE. O município também está localizado na mesorregião da 


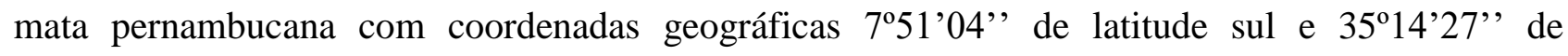
longitude oeste e $184 \mathrm{~m}$ de altitude. O clima predominante na região é do tipo As', tropical chuvoso com verão seco, precipitação média anual de $1.100 \mathrm{~mm}$ e temperatura média anual de $24,2{ }^{\circ} \mathrm{C}$ (Koffler et al., 1986). O solo do ensaio foi classificado como Argissolo Vermelho Amarelo distrocoeso (Santos et al., 2013).

\section{Avaliação do período do ciclo da cana-de-açúcar ideal para realização da coleta de folhas para avaliar a ARN em experimentos de campo}

ARN foi avaliada nas folhas das variedades de cana-de-açúcar RB 867515 e RB 92579 no primeiro ciclo de cultivo. As variedades foram dispostas em oito parcelas distribuídas casualmente em campo, quatro para cada variedade. A parcela foi composta por sete sulcos de $10 \mathrm{~m}$ de comprimento, espaçados por um metro, totalizando $70 \mathrm{~m}^{2}$. A área útil foi formada pelos cinco sulcos centrais, descartando-se um metro das extremidades, totalizando $40 \mathrm{~m}^{2}$.

Aos 70, 100, 130, 200 e 365 dias após o plantio (DAP) foi realizada a coleta de três folhas +1 por parcela às $9 \mathrm{~h}$, de acordo com o método proposto por Hagemam e Reed (1980), adaptado por Bezerra Neto e Barreto (2011). As folhas foram acondicionadas e levadas para o laboratório para determinação da ARN.

\section{Avaliação da posição ideal da folha de cana-de-açúcar para avaliar a ARN}

As folhas da cana-de-açúcar são classificadas de acordo com a visualização do colarinho e da lígula (Raij e Cantarella, 1997). Desse modo, a folha mais jovem a se visualizar o colarinho e a lígula é denominada de folha $+1(\mathrm{~F}+1)$; a folha antecedente é chamada de folha zero (F0); as demais são classificadas seguindo a mesma ordem e são denominadas de folha $+2(\mathrm{~F}+2)$, folha $+3(\mathrm{~F}+3)$, folha $+4(\mathrm{~F}+4)$, folha $+5(\mathrm{~F}+5)$ e folha $+6(\mathrm{~F}+6)$.

No centro de um canavial comercial da variedade RB 867515 foi delimitada uma parcela de $30 \mathrm{~m}^{2}$ para realização da amostragem do ensaio. Quatro folhas nas posições $\mathrm{F} 0, \mathrm{~F}+1, \mathrm{~F}+2, \mathrm{~F}+3$, $\mathrm{F}+4, \mathrm{~F}+5$ e F+6 foram coletadas 180 DAP. As folhas foram coletadas aleatoriamente em quatro plantas às 9 h. Neste ensaio, apesar do método proposto por Hagemam e Reed (1980), adaptado por Bezerra Neto e Barreto (2011) recomendar três folhas por parcela, optou-se por coletar quatro folhas em cada posição na planta, para que um maior número de amostras possa representar melhor a definição da posição mais adequada de coleta da folha. 


\section{Avaliação da coleta do número ideal de folhas para representar uma parcela e avaliar a ARN}

O ensaio foi realizado em canavial da variedade de cana-de-açúcar RB 763710 aos seis meses de idade no terceiro ciclo de cultivo, delimitando-se uma área de $90 \mathrm{~m}^{2}$ composta por nove sulcos com de $10 \mathrm{~m}$ de comprimento. No entanto, para as amostragens foram desconsiderados os dois sulcos de cada lateral e um metro de suas extremidades, formando-se uma área útil de $30 \mathrm{~m}^{2}$. Foi realizada uma coleta sistemática da folha +1 às $9 \mathrm{~h}$ de três plantas no centro do sulco, espaçadas a cada dois metros uma da outra, em cinco sulcos, totalizando 15 amostras. As folhas foram acondicionadas e levadas para o laboratório para determinação da ARN.

\section{Avaliação do período do dia ideal para realização da coleta de folhas para avaliar a ARN}

Folhas das variedades RB 763710 e RB 867515 foram coletadas durante dois dias das 6 às $18 \mathrm{~h}$, com intervalos de duas horas entre cada amostragem. Delimitou-se uma parcela para cada variedade com nove sulcos e $10 \mathrm{~m}$ de comprimento, totalizando $90 \mathrm{~m}^{2}$. No entanto, as coletas foram realizadas nos cinco sulcos centrais, desprezando-se um metro de cada extremidade.

Em cada período amostral foram coletadas três folhas +1 em três plantas no centro do sulco, espaçadas a cada dois metros uma da outra, totalizando 15 amostras. Neste ensaio, apesar do método proposto por Hagemam e Reed (1980), adaptado por Bezerra Neto e Barreto (2011) recomendar três folhas por parcela, optou-se por coletar 15 folhas, porque o aumento do número de amostras aumenta a precisão do ensaio, corroborando para uma melhor definição do período do dia mais adequado para coleta da folha.

\section{Procedimentosa estatísticos}

Visando a eliminação de comportamentos específicos de genótipos e de clima, e a maior representação de variedades para indicar procedimentos médios de amostragem para a determinação da ARN, no primeiro e quarto ensaios os valores da ARN foram transformados em dados relativos, sendo criada a atividade relativa da redutase do nitrato (ARRN). No primeiro ensaio essa transformação foi realizada em cada variedade e em cada fase do ciclo de cultivo da cana-deaçúcar; no quarto ensaio em cada variedade e em cada período dos dias de avaliação da ARN. A ARRN foi submetida a análise de variância (ANAVA) como medidas repetidas no tempo. Para isso foi utilizado o pacote estatístico SAS Learning 2.0, seguindo o procedimento para modelo misto, sendo selecionado o teste de covariância [AR(1), Ante (1), ARH (1), ARMA (1), CS, CSH, HF, TOEP, Lin (1), UN] que apresentou o menor valor do critério de Akaike (Wolfinger e Chang, 1995). 
Análise de regressão em função do tempo foi realizada, quando houve efeito significativo na ANAVA $(p<0,05)$, selecionando-se o modelo que apresentou parâmetros significativos $(p<0,05)$ e o mais alto coeficiente de determinação $\left(\mathrm{R}^{2}\right)$. No segundo ensaio a ARN nas diferentes folhas foi submetida à análise de variância (Teste $\mathrm{F}, \mathrm{p}<0,05)$, no delineamento inteiramente casualizado, e ao teste de comparação de médias de $\operatorname{Scott-Sknott~}(\alpha, \mathrm{p}<0,05)$. No terceiro ensaio o número de folhas necessárias para estimar a média da $\mathrm{ARN}$ da área (n) foi calculado pela seguinte fórmula: $\mathrm{N}=\left(\mathrm{t} \alpha^{*}\right.$ $\mathrm{CV} / f)^{2}$, em que: $\mathrm{t}_{\alpha}$ é valor tabelado da distribuição de $\mathrm{t}$ de Student para uma probabilidade $\alpha$ e graus de liberdade (n-1); CV é o coeficiente de variação; e $f$ é o limite de variação aceitável em relação à média, segundo Barreto et al. (1974).

\section{Resultados e Discussão}

\section{Avaliação do período do ciclo da cana-de-açúcar ideal para realização da coleta de folhas para avaliar a ARN em experimentos de campo}

Os dados da ARRN na folha durante o ciclo de cana planta se ajustaram ao modelo de sino. Assim, foi possível a seleção do período do ciclo da cultura em que ocorreu a máxima expressão da enzima (Figura 1). A ARRN no tecido foliar das variedades de cana-de-açúcar se elevou a partir dos 54 DAP, atingindo a máxima atividade aos 98 DAP, e em seguida iniciou uma fase de declínio, alcançando a estabilização por cerca de 150 DAP (Figura 1). Desse modo, é recomendável que as avalições da ARN pelo método in vivo ocorram entre 95 e 100 DAP.

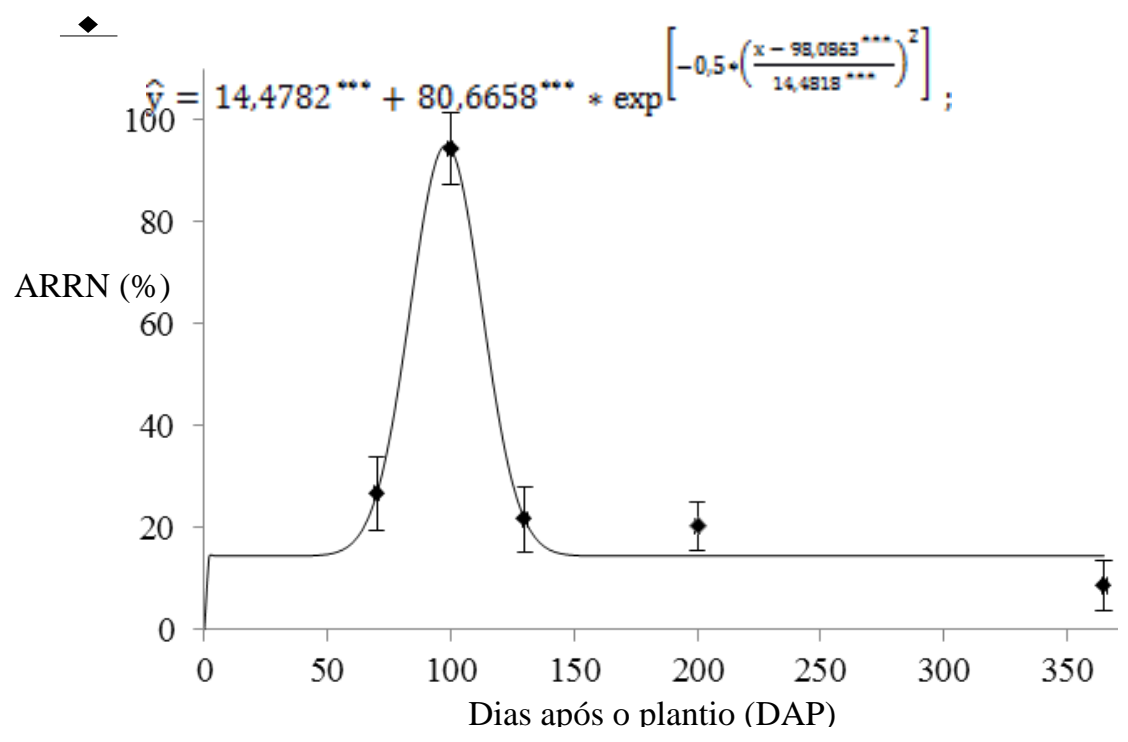


Figura 1. Atividade relativa da redutase do nitrato (ARRN) em folha de cana-de-açúcar, RB867515 e RB92579, em função dos diferentes períodos do primeiro ciclo de cultivo (cana planta). Barra de erros (I).

Nesse estudo a ARN em cana-de-açúcar no primeiro ciclo de cultivo se comportou conforme observaram Silveira e Crocomo (1990), quando avaliaram a ARN na folha da variedade NA 5679 e constararam que a atividade da enzima foi máxima em torno dos 100 DAP, decrescendo após esse período. A maior ARN próxima aos 100 DAP está relacionada com maiores concentrações de proteínas e com maior crescimento de área foliar. Silveira e Crocomo (1990) ainda constaram que, quando se aplicaram $20 \mathrm{~kg} \mathrm{ha}^{-1}$ de $\mathrm{N}$, a concentração de proteínas no colmo, folha e baínha da folha e a concentração de nitrato no colmo e na baínha da folha, apresentaram o mesmo comportamento da ARN, tendo sido máximos próximos aos 100 DAP.

\section{Avaliação da posição ideal da folha de cana-de-açúcar para avaliar a ARN}

A ARN da folha $0(\mathrm{~F} 0)$ a $+6(\mathrm{~F}+6)$ variou entre 0,041 e $0,051 \mu \mathrm{mol} \mathrm{NO}_{2} \mathrm{~g}^{-1} \mathrm{~h}^{-1}$ e teve média de $0,046 \mu$ mol $\mathrm{NO}_{2} \mathrm{~g}^{-1} \mathrm{~h}^{-1}$ (Figura 2). Entretanto, a ARN não se diferenciou com a posição das folhas, ou seja, para a determinação da atividade da enzima em folhas de cana-de-açúcar pode-se utilizar o tecido de qualquer folha da planta.

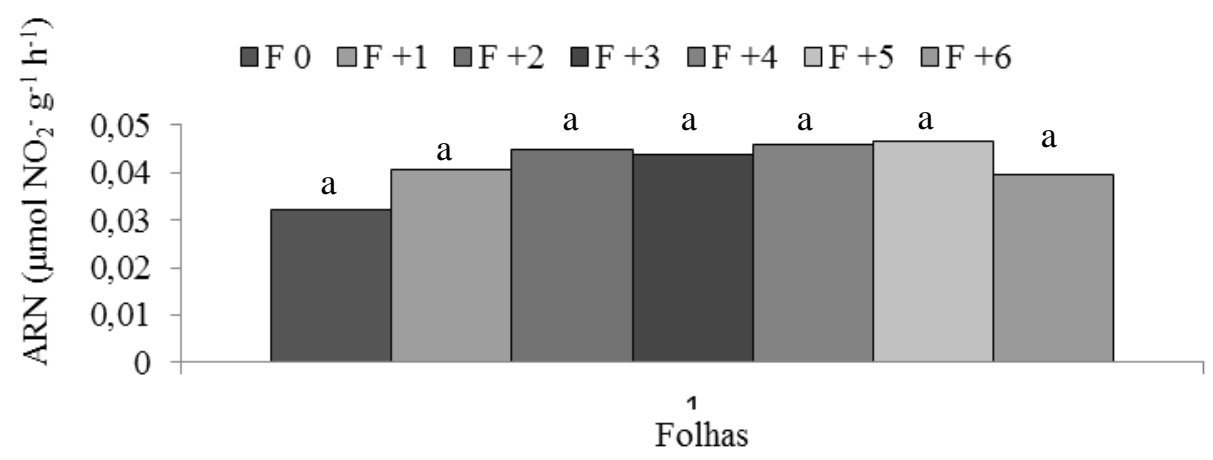

Figura 2. Atividade da redutase do nitrato (ARN) em diferentes folhas de cana-de-açúcar. Letras iguais não diferem entre si pelo teste $\mathrm{F}(\mathrm{p}<0,05)$.

Esses resultados diferem dos resultados encontrados por Santos et al. (2014), quando avaliaram a ARN nas diferentes folhas da cana-de-açúcar. Os autores constataram que a maior ARN ocorreu nas folhas mais jovens $(\mathrm{F} 0, \mathrm{~F}+1, \mathrm{~F}+2$ e $\mathrm{F}+3)$ e as menores nas folhas mais velhas $(\mathrm{F}+4, \mathrm{~F}+5$ e F+6). O estudo foi realizado com a variedade IACSP 933046 em cultivo de segundo ciclo e as amostras foram coletadas aos 180 DAP, quando a ARN nessa variedade ainda era elevada (cerca de $\left.0,5 \mu \mathrm{mol} \mathrm{NO}{ }^{-} \mathrm{g}^{-1} \mathrm{~h}^{-1}\right)$.

No trabalho realizado por Santos et al. (2014) também correu uma redução da ARN com o tempo, no entanto, essa redução foi menos acentuada do que nesse estudo. É possível que nesse 
caso tenha havido um efeito varietal e de ciclo de cultivo, porque nesse estudo as variedades utilizadas foram a RB 867515 e a RB 92579 e a ARN foi avaliada no primeiro ciclo de cultivo.

\section{Avaliação da coleta do número ideal de folhas para representar uma parcela e avaliar a ARN}

O número de amostras simples necessárias para formar uma amostra composta aumentou à medida que o limite de variação em relação à média $(f)$ diminuiu, ou seja, quanto menor a tolerância ao erro, maior deve ser o número de folhas a serem coletadas para representar uma parcela.

(Figura 3). Desse modo, número de amostras (n) foi em média de 56 e 1, para valores de $f$ de $10 \%$ e $90 \%$, respectivamente.

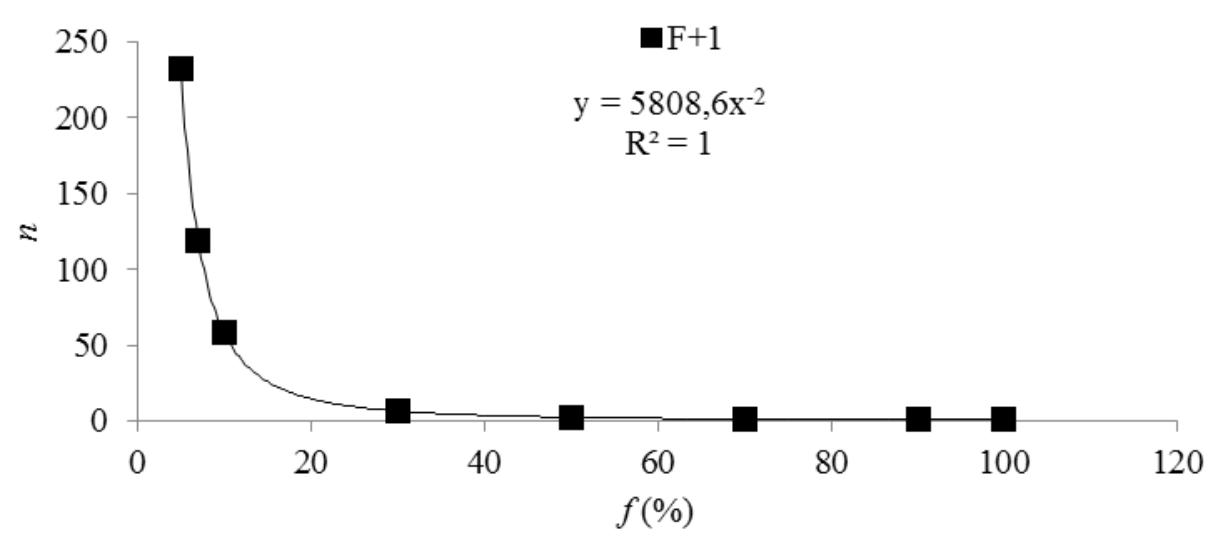

Figura 3. Número de amostras simples $(n)$ em função limite de variação em relação à média $(f)$ e utilizado para compor uma amostra composta de folhas para determinação da atividade da redutase do nitrato (ARN) em cana-de-açúcar.

Considerando um valor de $f$ de $20 \%$, indicado para estimar o $n$ em amostragens de solo (Hernandes et al., 2011), seria necessária a coleta de 15 folhas para representar uma parcela. Quando se aumentou $f$ para $50 \%$, três folhas foram suficientes para representar uma parcela, nas condições experimentais em que o ensaio foi conduzido.

É importante que o tamanho da parcela útil seja considerado quando for tomada a decisão sobre que valor de $f$ vai ser atribuído, pelo impacto que isso causa no tamanho da amostra. Adicionalmente, a amostragem deve ser realizada com o maior número de amostras possível, principalmente quando a avaliação da ARN for uma variável de fundamental importância na pesquisa que estiver sendo realizada. 


\section{Avaliação do período do dia ideal para realização da coleta de folhas para avaliar a ARN}

Os dados da ARRN em função de sua mensuração nas diferentes horas do dia se ajustaram a um modelo quadrático e a equação de regressão estimada representou $84 \%$ dos dados (Figura 4). A partir das primeiras horas de avaliação, a ARN mostrou-se crescente, atingindo a sua máxima expressão as 12:21 h e posteriormente, declinou até as $18 \mathrm{~h}$, quando atingiu 18,4\% de sua expressão máxima.

Os resultados encontrados neste estudo diferem de outras pesquisas. Foi relatado que a atividade da enzima é máxima após o tecido vegetal receber três a quatro horas de luz (Hagemam e Reed, 1980 adaptado por Bezerra Neto e Barreto, 2011), o que só aconteceu nesse estudo com, aproximadamente, sete horas de luz.

Entretanto, os resultados encontrados por Santos et al. (2014) corroboram o comportamento da ARN deste trabalho. Segundo os autores, a ARN em folhas de cana-de-açúcar é máxima em torno de 13 h devido a maior intensidade de radiação. Desse modo, a ARN é máxima quando a intensidade da radiação é maior e não devido ao tempo de exposição do tecido a luz. Segundo Crawford et al. (2000) a redução da ARN com a diminuição da intensidade luminosa é devido a fosforilação da enzima.

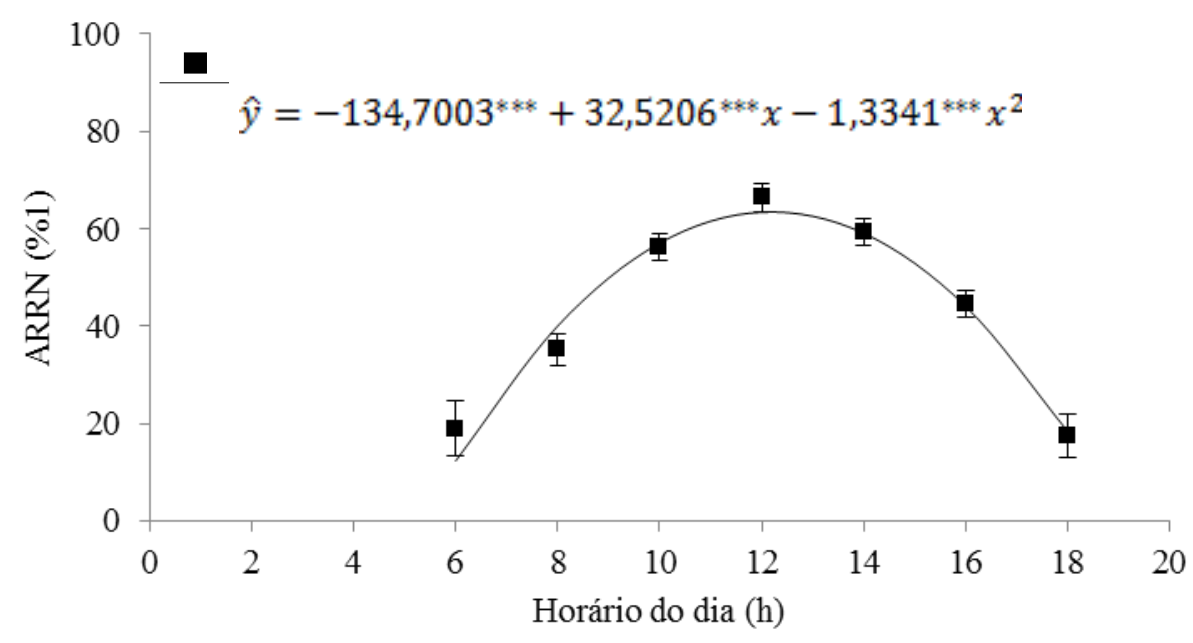

Figura 4. Atividade relativa da redutase do nitrato (ARRN) em função do horário do dia em folha de cana-de-açúcar. Barra de erros (I).

\section{Conclusões}

A avaliação da ARN pelo método in vivo em cana-de-açúcar deve ocorrer entre 95 e 100 DAP e pode ser realizada em qualquer folha verde da planta. 
Em experimentos de campo com cana-de-açúcar em que a parcela útil seja $\leq 30 \mathrm{~m}^{2}$, a tolerância da variação em relação à média $(f)$ seja de $20 \%$ e a probabilidade do t Student seja de 95\%, recomenda-se a coleta de 15 folhas por parcela para formação de uma amostra composta.

A coleta de folhas para avaliação da ARN deve ocorrer entre 12:00 e 12:30 h.

\section{Referências}

AHMAD S, FAZILI IS, HAQUE R, KHAN SN, ABDIN MZ. Standardization and estimation of nitrate reductase activity in the leaves of Ammi majus L. (Bishops weed) in relation to Sulphur deficiency and seed yield. Aust J Crop Sci; 4:515-22, 2010.

ARMAS R DE, VALADIER MH, CHAMPIGNY M., LAMAZE T. Influence of Ammonium and Nitrate on the Growth and Photosynthesis of Sugarcane. J Plant Physiol; 140:531-535, 1992.

AZEVEDO VM, BARBOSA D, FREIRE FJ, MARANGON LC, OLIVEIRA ECA, ROCHA AT, OLIVEIRA AC, VIEIRA MRS. Effects of different soil sampling instruments on assessing soil fertility in the Caatinga area, Brazil. Afr J Agric Res; 8:736-40, 2013.

BARBIERI V, SILVA FC, CASTRO A, GODOY AP. Modelos matemático-fisiológicos para estimativa da produtividade da cana-de-açúcar. In: Silva FC, Alves BJR, Freitas PL, editores. Sistema de produção mecanizada da cana-de-açúcar integrada à produção de energia e alimentos. Brasília, Embrapa; p.436-89, 2015.

BARRETO AC, NOVAIS RF, BRAGA JM. Determinação estatística do número de amostras simples de solo por área para avaliação de sua fertilidade. Rev. Ceres; 2:142-47,1994.

BEZERRA NETO E, BARRETO LP. Análises Químicas e Bioquímicas em Plantas. Recife: Editora Universitária da UFRPE; 2011.

BOBADE SN, KHYADE VB. Influence of inorganic nutrients on the activity of enzyme, nitrate reductase in the leaves of mulberry, Morus alba (L) (M-5 variety). Res J Recent Sci; 1:14-21, 2012.

CAMPBELL WH. Nitrate reductase structure, function and regulation: Bridging the Gap between Biochemistry and Physiology. Annu Rev Plant Physiol Plant Mol Biol; 50:277-303, 1999.

CARVALHO PG, AIDAR MPM, ZAIDAN LBP, CARVALHO MAM. Aspectos do crescimento e atividade da redutase do nitrato em plantas de Vernonia herbacea (Vell.) Rusby submetidas a diferentes fontes de nitrogênio. Hoehnea; 33:89-97, 2006.

CAZETTA JO, VILLELA LCV. Nitrate reductase activity in leaves and stems of tanner grass (Brachiaria radicans (Napper). Sci Agric; 61:640-48, 2004. 
CHANDA SV. Factors affecting nitrate reductase activity in some monocot and dicot species. J. Plant Biol; 46:41-5, 2003.

CONAB - Companhia Nacional de Abastecimento. Acompanhamento da safra brasileira: Cana-deaçúcar SAFRA 2015/16. Brasília: Conab; 2015.

CPRM - Serviço Geológico do Brasil. Projeto cadastro de fontes de abastecimento por água subterrânea. Diagnóstico do município de Vitória de Santo Antônio, estado de Pernambuco, p. 11, 2005.

FREIRE FJ, SILVA FC, ALVAREZ VENEGAS VH. Modelagem para fertilização e calagem na cultura de cana-de-açúcar. In Silva FC, Alves BJR, Freitas PL, editores. Sistema de produção mecanizada da cana-de-açúcar integrada à produção de energia e alimentos. Brasília, Embrapa; p.490-547, 2015.

HAGEMAN RH, REED AJ. Nitrate reductase from higher plants. San Diego: Academic Press; 1980.

HEMAPRABHA G, SIMON S, LAVANYA DL, SAJITHA B, VENKATARAMANA S. Evaluation of Drought Tolerance Potential of Elite Genotypes and Progenies of Sugarcane (Saccharum sp. hybrids). Sugar Tech; 15:9-16, 2013.

Holland DA, Little RC, Allen M, Dermott W. Soil and leaf sampling in apple orchards. J. hort. Sci; 42:403-17, 1967.

LI-PING W, YANG-RUI L, LI-TAO Y. Effects of molybdenum on nitrogen metabolism of sugarcane. Sugar Tech; 9:36-42, 2007.

OLIVEIRA ECA, FREIRE FJ, OLIVEIRA RI, OLIVEIRA AC, FREIRE MBGS. Acúmulo e alocação de nutrientes em cana-de-açúcar. Cienc Agron; 42:579-88, 2011.

ORLANDO FILHO J, CAMPOS H. Número ideal de folhas para a diagnose foliar em cana-deaçúcar (cana-planta). Brasil Açuc; 85:10-7, 1975a.

ORLANDO FILHO J, CAMPOS H. Número ideal de folhas para a diagnose foliar em cana-deaçúcar (soqueira). Brasil Açuc; 85:23-28, 1975b.

ROSSETTI AG, ALMEIDA JIL, PARENTE JIG, BARROS LM. Tamanho ótimo de parcela para experimentos com cajueiro comum. Rev Bras Frutic; 13:117-22, 1991.

ROZANE DE, NATALE W, PRADO RM, BARBOSA JC. Tamanho da amostra foliar para avaliação do estado nutricional de goiabeiras com e sem irrigação. R. Bras. Eng. Agríc. Ambiental; 13:233-39, 2009.

SANTOS CLR, CAZETTA JO, SARAN LM, SANCHES A. Otimização da análise da atividade da redutase do nitrato e sua caracterização em folhas de cana-de-açúcar. Pesqui. Agropecu. Bras; 49:384-94, 2014.

SANTOS HG, JACOMINE PKT, ANJOS LHC, OLIVEIRA VA, LUMBRERAS JF, COELHO MR, ALMEIDA JA, CUNHA TJF, OLIVEIRA JB. Sistema brasileiro de classificação de solos. 
3nd ed. rev. ampl. Brasília: Embrapa; 2013.

SILVEIRA JAG, CROCOMO OJ. Assimilação de nitrogênio em cana-de-açúcar cultivada em presença de elevado nível de $\mathbf{N}$ e de vinhaça no solo. Braz. J. Plant Physiol; 2:7-15, 1990.

SMIT MA, SINGELS A. The response of sugarcane canopy development to water stress. Field Crops Res; 98:91-7, 2006.

TRIVELIN PCO, FRANCO HCJ, OTTO R, FERREIRA DA, VITTI AC, FORTES C, FARONI CE, OLIVEIRA ECA, CANTARELLA H. Impact of sugarcane trash on fertilizer requirements for São Paulo, Brazil. Sci Agric; 70:345-52, 2013. 